\title{
Generations, Communication and Media Philosophy
}

\author{
The $18^{\text {th }}$ Nordic Conference \\ on Media and Communication Research
}

A distinguishing generational experience is a precondition for belonging to a certain generation. The 1960s was a time of great changes in media research as youth culture, rock and film had an impact on the interests of researchers. The Vietnam war in the 1970s speeded up the consideration of media ethics and at least in Finland the turn of the 1980s and 1990s is remembered as the beginning of financial recession. The interaction of technology and culture, mediation and global networks are setting new demands for media ethical and media philosophical considerations in the $21^{\text {st }}$ century. The links between media and power have become more complicated and invisible than before.

The Internet has revolutionized the research of media and created a new generation of researchers whose minds are occupied with media philosophical questions, such as What is media? What is mediation? What is mediated activity? While the marxist philosophy of the 1970s was considering the influences that the society system had on the actions of people, in the $21^{\text {st }}$ century one must cross boarders of nations and societal forms and pay attention to functional contexts and networks worldwide. Media research has entered a new phase where influences are adapted from different sources and research is taking place even more on no-mans land, for instance in societies and by using the new web technology. Face-to-face interaction has changed into computer-to-computer communication.

One distinctive feature of the change of generation can also be an important event that shakes a person so profoundly that it can crucially change his/her world of thoughts and values. The media researchers of my own generation are connected, not only by Nordic conferences, but also by societal crisis like the collapse of the socialistic system in Europe, the unification of Europe and the digitalization of media. The reporting of global catastrophes in media can also produce generation based experiences.

The Nordic Conferences on Media and Communication Research have functioned as a meeting point and a crossroad already for quite some generations. The conferences that begun in Voksenåsen, Norway in 1973 have discussed current issues about communication and media research. Although modern communication technology can replace face-to-face meetings, it can't deliver the humane forms of interaction even at its best. The interaction between the different generations of researchers has to be cherished in a concrete place and atmosphere. The younger generation of researchers is still in the need of support and opportunities for meeting other researchers. The conference is a special opportunity to say out ones thoughts aloud and for communication with the researchers of the field, which can result in new ideas and forms of interaction. The conference is medium par excellence.

\section{Irma Kaarina Halonen}

President (2006-2008)

TOY Finnish Association for Mass Communication Research 